\title{
Perbandingan Anestesi Spinal Menggunakan Bupivakain Hiperbarik dengan Levobupivakain Isobarik pada Seksio Sesarea
}

\author{
I Made Artawan', Budi Yulianto Sarim ${ }^{1}$, Sidarta Sagita², Maria Agnes Etty Dedi \\ ${ }^{1}$ Departemen/SMF Anestesi dan Terapi Intensif Fakultas Kedokteran Universitas Nusa Cendana-RSU Prof. \\ Dr. W.Z. Johannes Kupang, ${ }^{2}$ Departemen Ilmu Kesehatan Masyarakat dan Kedokteran Komunitas, Fakultas \\ Kedokteran Universitas Nusa Cendana Kupang
}

\begin{abstract}
Abstrak
Latar Belakang: Bupivakainhiperbarikmerupakan anestesilokalpalingsering digunakanuntukanestesispinal seksio sesarea. Namun memiliki efek samping buruk pada jantung dan susunan saraf pusat. Levobupivakain merupakan enansiomer murni bupivakain rasemik dan memiliki sifat kurang toksik bagi jantung dan susunan saraf pusat. Tujuan: Penelitian ini bertujuan membandingkan onset dan durasi blok sensorik dan motorik serta efek samping penggunaan Bupivakain hiperbarik dan Levobupivakain isobarik pada seksio sesarea.

Subyek dan Metode: Satu penelitian klinis tersamar tunggal. Subyek penelitian ditentukan dengan consecutive sampling yang memenuhi kriteria inklusi dan eksklusi .Subyek dibagi dua kelompok, 43 subyek kelompok Bupivakain Hiperbarik $10 \mathrm{mg}(\mathrm{BH})$ dan 43 subyek kelompok Levobupivakain Isobarik $10 \mathrm{mg}$ (LI). Kedua kelompok dibandingkan onset dan durasi blok sensorik dan motorik, kejadian hipotensi, menggigil, bradikardia dan mual muntah. Uji statistik perbandingan rerata antar kedua kelompok dilakukan uji Mann Whitney. Hasil: Onset blok sensorik dan motorik signifikan lebih cepat pada kelompok $\mathrm{BH}(\mathrm{p}<0,001)$, sedangkan durasi blok sensorik dan motorik signifikan lebih pendek pada LI ( $\mathrm{p}<0,001)$. Hipotensi lebih banyak terjadi pada $\mathrm{BH}$ (34,9\%) dibandingkan LI (25,6\%), kejadian menggigil lebih banyak pada BH (4,7\%) dibandingkan LI (2,3\%). Tidak ditemukan kejadian bradikardia dan mual muntah.

Simpulan: Levobupivakain isobarik $10 \mathrm{mg}$ memiliki onset blok sensorik dan motorik yang lebih lambat dengan durasi lebih pendek dibandingkan Bupivakain hiperbarik $10 \mathrm{mg}$ untuk anestesi spinal pada seksio sesarea dengan efek samping yang minimal
\end{abstract}

Kata kunci: anestesi spinal, bupivakain hiperbarik, levobupivakain hiperbarik, seksio sesarea

\section{Comparison of Spinal Anesthesia Using Hyperbaric Bupivacaine and Isobaric Levobupivacaine in Caesarean Section}

\begin{abstract}
Background: Hyperbaric bupivacaine is a local anesthetic often used spinal anesthesia in cesarean section. However bupivacaine have worse side effects on the heart and central nervous system. Levobupivacaine is a pure enantiomer of racemic bupivacaine and less toxic to the heart and central nervous system

Objective:This study aims to compare the onset and duration of sensory and motor blocks as well as the side effects that occur with the use of hyperbaric bupivacaine and isobaric levobupivacaine in cesarean section.

Subject and methods: This study is a single blind clinical trial. The research subjects were determined of consecutive sampling that met the inclusion and exclusion criteria. Subjects were divided two groups, 43 subjects in the $10 \mathrm{mg}$ Hyperbaric Bupivacaine (BH) and 43 subjects in the $10 \mathrm{mg}$ Isobaric Levobupivacaine (LI). In both groups were compared onset and duration of sensory and motor blocks, incidence hypotension, shivering, bradycardia and nausea and vomiting. The statistical test using the Mann Whitney test

Results: The sensory and motor block onset significantly faster in the $\mathrm{BH}(\mathrm{p}<0.001)$, while the duration of sensory block and motor block significantly shorter in the LI ( $\mathrm{p}<0.001)$. Hypotension was more in the BH $(34.9 \%)$ than LI $(25.6 \%)$, incidence of shivering was more in the BH (4.7\%) than LI (2.3\%). There were no incidence bradycardia, nausea and vomiting.. Conclusion:Isobaric levobupivacaine $10 \mathrm{mg}$ has a slower onset of sensory and motor blocks with shorter duration than hyperbaric bupivacaine $10 \mathrm{mg}$ for spinal anesthesia in cesarean section
\end{abstract}

Key words: spinal anesthesia, hyperbaric bupivacaine, isobaric levobupivacaine, cesarean section.

This article is licensed under a

Creative Commons Attribution-NonCommercial-ShareAlike 4.0 International License.

JAOI 2021;4(2): 93-9

CI Made A, Budi Yulianto S, Sidarta Sagita, Maria Agnes Etty D

(2021) under the CC-BY-NC-SA license 


\section{Pendahuluan}

Penggunaan obat anestesi lokal levobupivakain isobarik ini masih terbilang cukup baru dan masih belum banyak dipergunakan secara luas seperti halnya obat anestesi lokal bupivakain hiperbarik pada pembedahan seksio sesarea. Meskipun penggunaan levobupivakain untuk anestesi spinal telah dijelaskan dengan baik dalam literatur, namun sangat sedikit penelitian telah meneliti efek levobupivakain dalam anestesi obstetri. ${ }^{1}$ Penelitian mengenai perbandingan efektifitas dan efek samping pengunaan levobupivakain isobarik dengan bupivakain hiperbarik untuk anestesi spinal pada kasus seksio sesarea juga masih belum banyak dilakukan.

Oleh karena itu peneliti tertarik untuk meneliti lebih lanjut perbandingan efek penggunaan levobupivakain isobarik dibandingkan dengan bupivakain hiperbarik untuk anestesi spinal pada pembedahan seksio sesarea. Pada tahun 2015 dilakukan penelitian uji klinis tersamar ganda membandingkan efek penggunaan bupivakain hiperbarik dengan levobupivakain isobarik untuk anestesi spinal pada pembedahan seksio sesarea. Hasil penelitian ini menyebutkan bahwa durasi blok sensorik dan motorik secara signifikan lebih pendek pada kelompok levobupivakain dan tinggi blok sensorik maksimal signifikan lebih rendah pada kelompok levobupivakain. Kejadian efek samping hipotensi, bradikardia dan mual muntah lebih rendah pada kelompok levobupivakain. ${ }^{2}$

Penelitian perbandingan efek penggunaan obat anestesi lokal levobupivakain isobarik dengan bupivakain hiperbarik untuk anestesi spinal pada pembedahan seksio sesarea di Indonesia telah dilakukan pada tahun 2014. Hasil penelitian ini menunjukkan bahwa waktu pulih blok motorik secara signifikan lebih cepat pada kelompok levobupivakain, namun kejadian efek samping berupa hipotensi, menggigil, mual dan muntah tidak ada perbedaan yang bermakna. ${ }^{3}$ Penelitian ini bertujuan untuk membandingkan onset dan durasi blok sensorik dan blok motorik serta efek samping berupa hipotensi, bradikardia, mual muntah dan menggigil yang terjadi pada penggunaan bupivakain hiperbarik dan levobupivakain isobarik pada seksio sesarea. Hipotesis penelitian ini yaitu 1). Penggunaan levobupivakain isobarik untuk anestesi spinal memiliki onset dan durasi blok sensorik dan motorik yang tidak berbeda bermakna dengan bupivakain hiperbarik; 2). Penggunaan levobupivakain isobarik untuk anestesi spinal memiliki efek samping hipotensi, bradikardia, mual muntah dan menggigil yang lebih kecil dibandingkan dengan bupivakain hiperbarik

\section{Subyek dan Metode}

Penelitian ini merupakan penelitian eksperimental dengan memakai uji klinis tersamar tunggal. Subyek penelitian diambil secara consecutive sampling. Subyek penelitian yang memenuhi kriteria inklusi dan eksklusi sebanyak 86 subyek, dibagi menjadi 2 kelompok subyek yaitu sebanyak 43 subyek kelompok perlakuan 1 (BH) yaitu kelompok yang menggunakan obat anestesi lokal bupivakain hiperbarik $0,5 \% 10 \mathrm{mg}(2 \mathrm{ml})$ untuk anestesi spinal pada seksio sesarea dan 43 subyek kelompok perlakuan 2 (LI) yaitu kelompok yang menggunakan obat anestesi lokal levobupivakain

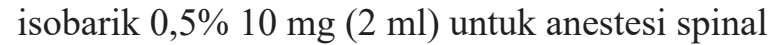
pada seksio sesarea. Kriteria inklusi meliputi pasien gravida dengan usia 16 tahun hingga 40 tahun dengan status fisik ASA 1 atau ASA 2 yang akan menjalani operasi seksio sesarea dengan anestesi spinal dan tidak ada kontraindikasi untuk dilakukan anestesi spinal.

Kriteria eksklusi meliputi pasien menolak berpartisipasi, kehamilan gemelli, tinggi badan $<150 \mathrm{~cm}$ atau $>170 \mathrm{~cm}$, berat badan $>100 \mathrm{~kg}$, riwayat alergi terhadap obat anestesi lokal. tekanan sistolik basal $<90 \mathrm{mmHg}$, preeklampsia dan pasien dengan kelainan jantung. Kriteria drop out meliputi pasien yang mengalami gagal blok spinal dan atau operasi memanjang lebih dari 2 jam. Penelitian ini dilaksanakan di RSIA Dedari Kupang setelah mendapatkan persetujuan penelitian (ethical clearence) dari Komisi Etik Penelitian Fakultas Kedokteran Universitas Nusa Cendana Kupang. Subyek yang memenuhi kriteria inklusi dan eksklusi kemudian dilakukan randomisasi masuk ke kelompok $\mathrm{BH}$ atau kelompok LI. Randomisasi dilakukan dengan 
alokasi random blok secara online pada situs https://www.randomizer.org/ yang dilakukan oleh pihak ketiga. Prosedur concealment dilakukan dengan cara menyimpan hasil randomisasi dalam amplop tertutup. Anestesi spinal dilakukan dalam posisi duduk dengan jarum spinal G26 pada level L3-4, kemudian dilakukan pin prick test pada garis midaxillar untuk menilai ketinggian blok sensorik. Onset blok sensorik diukur setiap menit dimulai saat selesai tindakan anestesi spinal sampai tercapai ketinggian blok sensorik setinggi segmen spinal thorakal 10. Onset blok motorik diukur setiap menit sampai tercapainya blok motorik komplit (Skor Bromage 3). Durasi blok sensorik diukur setiap 5 menit dimulai saat selesai tindakan anestesi spinal sampai terjadi regresi 2 segmen spinal.

Penilaian durasi blok motorik dilakukan dengan mengukur skor bromage setiap 5 menit dimulai saat telah terjadi blok motorik lengkap (skor bromage 3) sampai terjadi pemulihan blok motorik lengkap (skor bromage 0). Dilakukan juga pencatatan kejadian hipotensi, bradikardia, mual atau muntah dan kejadian menggigil selama operasi berlangsung. Hipotensi bila didapatkan penurunan tekanan darah sistolik lebih dari $20 \%$ nilai tekanan darah sistolik basal dan atau tekanan darah sistolik kurang dari $90 \mathrm{mmHg}$ setelah dilakukan anestesi spinal. Bradikardia bila terjadi penurunan laju denyut jantung di bawah $60 \mathrm{kali} / \mathrm{menit}$. Pengukuran terjadinya hipotensi dan bradikardia dilakukan dengan monitoring tekanan darah noninvasif dan EKG pada layar monitor. Menggigil bila ditemukan aktivitas kontraksi satu atau lebih kelompok otot. Analisa data menggunakan program SPSS versi 16 untuk Windows 10. Variabel yang berskala data numerik meliputi usia, berat badan, tinggi badan, onset dan durasi blok sensorik dan motorik digambarkan dengan rerata dan standar deviasi, sedangkan variabel yang berskala kategorikal digambarkan dengan jumlah dan persennya. Uji perbandingan rerata antar kedua kelompok untuk data yang berdistribusi normal dilakukan dengan uji Independent t-test, sedangkan untuk data yang tidak berdistribusi normal dilakukan dengan uji Mann Whitney.

\section{Hasil}

Jumlah keseluruhan subyek dalam penelitian ini yang memenuhi kriteria inklusi sebanyak 86 orang subyek dengan jumlah masingmasing kelompok berjumlah 43 orang subyek. Keseluruhan subyek yang terpilih tidak ada yang menolak berpartisipasi dan tidak ada yang tereksklusi sesuai dengan kriteria eksklusi. Pada saat dilakukan penelitian tidak ada subyek yang mengalami drop out, sehingga 86 orang subyek tersebut menjadi subyek eligible yang selanjutnya datanya akan dianalisis. Karakteristik subyek berdasarkan umur, tinggi badan, berat badan, durasi operasi dan status fisik ASA dicantumkan pada tabel 1 tentang karakteristik subyek pada kedua kelompok.

Onset blok sensorik pada kelompok BH signifikan lebih cepat dengan waktu 2,32 $\pm 0,47$ menit dibandingkan dengan kelompok LI dengan waktu 3,27 $\pm 0,66$ menit dengan nilai $\mathrm{p}<0,001$. Onset blok motorik pada kelompok BH juga tercapai signifikan lebih cepat pada kelompok $\mathrm{BH}$ dengan waktu 2,88 $\pm 0,49$ menit dibandingkan dengan kelompok LI dengan waktu 3,79 $\pm 0,59$ menit dengan nilai $\mathrm{p}<0,001$. Durasi blok sensorik signifikan lebih pendek pada kelompok LI dengan durasi 57,90 $\pm 5,69$ menit dibandingkan dengan kelompok $\mathrm{BH}$ dengan durasi 76,86 $\pm 5,77$ $(p<0,001)$. Demikian juga durasi blok motorik pada kelompok LI signifikan lebih pendek pada kelompok LI dengan durasi 91,39 $\pm 5,70$ menit dibandingkan dengan kelompok $\mathrm{BH}$ dengan durasi $117,91 \pm 6,47$ menit $(p<0,001)$. Keadekuatan blok sensorik pada kedua kelompok tercapai untuk memfasilitasi pembedahan seksio sesarea. Kejadian hipotensi pada kelompok BH sebanyak 15 subyek dan pada kelompok LI sebanyak 11 subyek dengan nilai $\mathrm{p}=0,241$. Sedangkan kejadian menggigil pada kelompok BH ditemukan 2 orang subyek dan pada kelompok LI sebanyak 1 subyek. Tidak ditemukan kejadian bradikardia maupun mual muntah pada kedua kelompok.

\section{Pembahasan}

Pada penelitian ini dapatkan hasil bahwa terdapat 
Tabel 1 Karakteristik Subyek Berdasarkan Kelompok Perlakuan

\begin{tabular}{|c|c|c|c|c|}
\hline \multirow[t]{2}{*}{ Variabel } & & \multicolumn{2}{|l|}{ Kelompok } & \multirow[t]{2}{*}{ Nilai $p$} \\
\hline & & $\begin{array}{l}\text { Bupivakain Hiperbarik } \\
(\mathrm{BH}) \\
(\mathrm{n}=43\end{array}$ & $\begin{array}{l}\text { Levobupivakain } \\
\text { Isobarik (LI) } \\
(\mathrm{n}=43)\end{array}$ & \\
\hline Umur (tahun) & Rerata \pm SD & $28,32 \pm 3,2$ & $28,81 \pm 3,9$ & $0,527 \mathrm{a}$ \\
\hline Tinggi Badan $(\mathrm{cm})$ & Rerata \pm SD & $157,51 \pm 3,7$ & $156,28 \pm 4,6$ & $0,176 \mathrm{a}$ \\
\hline Berat Badan (kg) & Rerata \pm SD & $65,51 \pm 3,7$ & $65,65 \pm 5,1$ & $0,845 b$ \\
\hline Durasi Operasi (menit) & Rerata $\pm \mathrm{SD}$ & $41,51 \pm 2,3$ & $41,62 \pm 3,4$ & $0,528 \mathrm{~b}$ \\
\hline \multirow[t]{2}{*}{ Status Fisik ASA } & ASA $1(\%)$ & 0,0 & 0,0 & $>0,999 \mathrm{c}$ \\
\hline & ASA $2(\%)$ & 100 & 100 & \\
\hline
\end{tabular}

Keterangan: a: hasil uji t 2 subyek bebas; b: hasil uji Mann Whitney; c: hasil uji Chi-Square

Karakteristik umur, tinggi badan, berat badan, durasi operasi dan status fisik ASA pada kedua kelompok dapat dikatakanberdistribusinormaldenganmasing-masingnilaip $>0,05$. Berdasarkangambarankarakteristikvariabel tersebut diatas maka dapat disimpulkan bahwa kedua kelompok perlakuan sudah sebanding (comparable).

Tabel 2 Parameter Onset Blok Sensorik dan Motorik pada Kelompok Subyek

\begin{tabular}{lllll}
\hline Variabel & & $\begin{array}{l}\text { Kelompok } \\
\text { Bupivakain Hiperbarik (BH) } \\
(\mathrm{n}=43)\end{array}$ & $\begin{array}{l}\text { Levobupivakain } \\
\text { Isobarik (LI) } \\
(\mathrm{n}=43)\end{array}$ & Nilai p \\
& & $3,27 \pm 0,66$ & $<0,001 \mathrm{a}$ \\
\hline Onset blok sensorik (menit) & Rerata $\pm \mathrm{SD}$ & $2,32 \pm 0,47$ & $3,79 \pm 0,59$ & $<0,001 \mathrm{a}$ \\
\hline Onset blok motorik (menit) & Rerata $\pm \mathrm{SD}$ & $2,88 \pm 0,49$ & &
\end{tabular}

Keterangan: a: hasil uji Mann Whitney

Tabel 3 Parameter Durasi Blok Sensorik dan Motorik pada Kelompok Subyek

\begin{tabular}{lllll}
\hline Variabel & & $\begin{array}{l}\text { Kelompok } \\
\text { Bupivakain Hiper- } \\
\text { barik }(\mathrm{BH}) \\
(\mathrm{n}=43)\end{array}$ & $\begin{array}{l}\text { Levobupivakain } \\
\text { Isobarik (LI) } \\
(\mathrm{n}=43)\end{array}$ & Nilai $\mathrm{p}$ \\
& & & & \\
\hline Durasi blok sensorik (menit & Rerata \pm SD & $76,86 \pm 5,77$ & $57,90 \pm 5,69$ & $<0,001 \mathrm{a}$ \\
Durasi blok motorik (menit) & Rerata \pm SD & $117,91 \pm 6,47$ & $91,39 \pm 5,70$ & $<0,001 \mathrm{a}$ \\
\hline
\end{tabular}

Keterangan: a: hasil uji Mann Whitney

Tabel 4 Gambaran Efek Samping pada Subyek Penelitian

\begin{tabular}{llll}
\hline & $\begin{array}{l}\text { Kelompok } \\
\text { Bupivakain Hiperbarik }(\mathrm{BH}) \\
(\mathrm{n}=43\end{array}$ & $\begin{array}{l}\text { Levobupivakain Isobarik }(\mathrm{LI}) \\
(\mathrm{n}=43)\end{array}$ & Nilai $\mathrm{p}$ \\
\hline Hipotensi & 15 & 11 & $0,241 \mathrm{a}$ \\
Bradikardia & 0 & 0 & $>0,999$ \\
Mual/muntah & 0 & 0 & $>0,999$ \\
Menggigil & 2 & 1 & $0,500 \mathrm{a}$ \\
\hline
\end{tabular}

Keterangan: a: hasil uji Chi square 
perbedaan yang signifikan secara statistik onset blok sensorik dan motorik antara kelompok Bupivakain dengan kelompok levobupivakain dengan nilai $\mathrm{p}<0,001$. Hal ini sejalan dengan hasil penelitian yang dilakukan oleh tahun 2012 yang membandingkan anestesi spinal dengan bupivakain hiperbarik dengan levobupivakain isobaric untuk anestesi spinal pada pembedahan seksio sesarea didapatkan bahwa onset blok sensorik maupun motorik lebih cepat pada kelompok bupivakain hiperbarik dibandingkan dengan kelompok levobupivakain isobarik. ${ }^{4}$

Pada penelitian lain yang dilakukan tahun 2015 yang membandingkan anestesi spinal dengan bupivacaine hiperbarik $10 \mathrm{mg}+$ Fentanyl $25 \mathrm{mcg}$ dengan levobupivakain isobarik $10 \mathrm{mg}+$ Fentanyl 25 mcg juga didapatkan hasil bahwa onset bloksensorik dan motorik signifikan lebih cepat pada kelompok bupivakain hiperbarik. ${ }^{5}$ Hal ini sesuai dengan dasar teori bahwa kedua jenis obat anestesi local bupivakain dan levobupivakain merupakan obat anestesi lokal yang memiliki onset yang cepat dalam penggunaan untuk anestesi spinal. ${ }^{6,7}$ Pada pembedahan seksio sesarea onset bloksensorik dan motorik terjadi lebih lambat pada penggunaan levobupivakain dibandingkan dengan bupivakain. ${ }^{8}$

Durasi blok sensorik dan motorik pada penelitian ini didapatkan perbedaan yang signifikan antara kelompok $\mathrm{BH}$ dan kelompok LI dengan nilai $\mathrm{p}<0,001$. Durasi blok sensorik dan blok motorik secara signifikan lebih pendek pada kelompok LI dibandingkan dengan kelompok BH. Hal ini sesuai dengan penelitian yang dilakukan pada tahun 2015 yang membandingkan karakteristik bupivakain hiperbarik dengan levobupivakain isobarik pada anestesi spinal untuk pembedahan seksio sesarea, didapatkan hasil durasi untuk regresi dua segmen dan durasi blok motorik secara signifikan lebih pendek pada kelompok levobupivakain. ${ }^{2}$ Pada penelitian yang dilakukan pada tahun 2014 yang membandingkan waktu pulih blok motorik antara anestesi spinal menggunakan anestesi local bupivakain hiperbarik dengan levobupivakain isobaric didapatkan hasil bahwa waktu pulih blok motorik pada kelompok levobupivakain lebih pendek secara signifikan dibandingkan dengan waktu pulih motorik pada kelompok bupivakain. ${ }^{3}$ Pada satu penelitian juga didapatkan hasil durasi blok motorik lebih pendek pada kelompok levobupivakain isobaric dibandingkan dengan kelompok bupivakain hiperbarik namun tidak berbeda bermakna. ${ }^{12}$ Pada penelitian subyek yang menjalani pembedahan abdomen bawah didapatkan bahwa durasi blok sensorik signifikan lebih lama pada kelompok bupivakain hiperbarik, demikian juga blok motorik durasinya lebih lama pada kelompok bupivakain hiperbarik dibandingkan dengan kelompok levobupivakain isobaric namun perbedaannya tidak bermakna. ${ }^{11}$

Kejadian efek samping hipotensi lebih sedikit terjadi pada kelompok LI dibandingkan dengan kelompok $\mathrm{BH}$, namun perbedaannya secara statistic tidak berbeda bermakna. Hal ini sejalan dengan hasil penelitian peneliti lain dimana efek samping berupa hipotensi terjadi lebih sedikit pada kelompok Levobupivakain dibandingkan dengan kelompok Bupivakain. ${ }^{2}$ Demikian juga pada penelitian tahun 2016 dimana didapatkan kejadian hipotensi dan kebutuhan Efedrin signifikan lebih banyak terjadi pada kelompok yang menggunakan Bupivakain hiperbarik 12,5 mg dibandingkan dengan kelompok Levobupivakain 12,5 mg untuk anestesi spinal pada seksio sesarea. ${ }^{13}$

Kejadian bradikardia tidak ditemukan pada penelitian ini. Hal ini sejalan dengan hasil penelitiandari peneliti lain di mana kejadian bradikardia hanya di temukan pada 1 dari 30 subyek kelompok levobupivakain dan 4 dari 30 subyek pada kelompok bupivakain.1 Demikian juga pada pada penelitian kejadian bradikardia hanya di temukan pada 1 dari 30 subyek kelompok levobupivakain dan 5 dari 30 subyek pada kelompok bupivakain.Keduanya tidak berbeda bermakna diantara kedua kelompok. ${ }^{2}$ Kejadian mual muntah tidak ditemukan pada penelitian ini. Hal ini sesuai dengan hasil penelitian di tempat lain dimana kejadian mual muntah didapatkan terjadi hanya pada 1 dari 20 subyek pada kelompok levobupivakain isobarik, sedangkan pada kelompok bupivakain hiperbarik ditemukan pada 3 dari 20 subyek, dimana perbedaannya tidak berbeda bermakna pada kedua kelompok. ${ }^{12}$ 
Kejadian menggigil pada penelitian ini lebih banyak didapatkan pada kelompok bupivakain hiperbarik dibandingkan dengan kelompok levobupivakain isobaric namun tidak berbeda bermakna.

Keunggulan penelitian ini yaitu telah memperhitungkan faktor perancu yang sudah comparable saat dibandingkan antar kelompok. Selain hal tersebut setting penelitian ini berdasarkan penatalaksanaan rutin di rumah sakit sehingga hasil penelitian ini akan langsung dapat diterapkan (applicable). Kekurangannya pada penelitian ini tidak melakukan analisis terhadap ketinggian blok maksimal yang tercapai pada kedua kelompok subyek. Berdasarkan hasil yang didapatkan pada penelitian ini yang dapat diaplikasikan langsung dalam praktek klinik dalam melakukan anestesi spinal pada pembedahan seksio sesarea yaitu penggunaan levobupivakain isobaric memiliki durasi blok sensorik dan motorik yang lebih pendek sehingga bermanfaat untuk mobilisasi dini untuk pasien pasca bedah seksio sesarea.

\section{Simpulan}

Onset blok sensorik dan motorik signifikan lebih cepat pada kelompok bupivakain hiperbarik, sedangkan durasi blok sensorik dan blok motorik signifikan lebih pendek pada kelompok levobupivakain isobarik. Kejadian hipotensi lebih banyak terjadi pada kelompok bupivakain dibandingkan dengan kelompok levobupivakain namun tidak berbeda bermakna. Demikian juga kejadian menggigil lebih banyak terjadi pada kelompok bupivakain dibandingkan dengan kelompok levobupivakain namun juga tidak berbeda bermakna. Tidak ditemukan efek samping bradikardia dan mual muntah pada kedua kelompok. Penggunaan bupivakain hiperbarik $10 \mathrm{mg}$ maupun levobupivakain isobarik $10 \mathrm{mg}$ efektif digunakan untuk anestesi spinal pada pembedahan seksio sesarea dengan efek samping yang minimal.

Ucapan Terima Kasih

Pada kesempatan ini peneliti mengucapkan terima kasih untuk manajemen RSIA Dedari Kupang yang sudah mengijinkan penelitian ini dilakukan di kamar operasi RSIA Dedari Kupang. Penelitian ini mendapatkan pendanaan penuh dari Universitas Nusa Cendana Kupang.

\section{Daftar Pustaka}

1. Narayanappa AB, Gurulingaswamy S, Prabhakaraiah UN. A retrospective comparison of intrathecal levobupivacaine with bupivacaine for elective lower segment cesarean section. Anaesth Pain \& Intensive Care 2016;20(1):26-31.

2. Duggal R, Kapoor R, Moyal G. A comparison of intratetchal levobupivacaine with hyperbaric bupivacaine for elective cesarean section: A prospective randomized doble-blind study. J Obstet Anaesth Crit Care 2015;5:78-83.

3. Ervina Y. Tesis: Perbandingan waktu pulih hambatan motorik antara pemberian levobupivakain $\quad 0,5 \% \quad 10 \quad \mathrm{mg}$ dengan bupivakain $0,5 \% 10 \mathrm{mg}$ pada seksio sesarea dengan anestesi blok subarakhnoid di RSUP Sanglah Denpasar. Program Studi Ilmu Biomedik Program Pascasarjana Universitas Udayana. Denpasar; 2014.

4. Guler $G$ et al. A Comparison of Spinal Anesthesia with Levobupivacaine and Hyperbaric Bupivacaine for Cesarean Sections: A Randomized Trial. Open Journal of Anesthesiology, 2012, 2, 84-89.

5. Goyal A, Shankaranarayan P, Ganapathi. A randomized clinical study comparing spinal anesthesia with isobaric levobupivacaine with fentanyl and hyperbaric bupivacaine with fentanyl in elective cesarean sections. Anesthesia: Essays and Researches; 9(1); 2015; 9(1).

6. Maheswari K, Naguib MA. Local Anesthetic In: Stoelting's Pharmacology and Physiology in Anesthetic Practice 5th ed. USA: Wolter's Kluwer Health; 2015, 305-6

7. Bajwa SJS, Kaur J. Clinical profile of 
levobupivacaine in regional anesthesia: A systematic review. Journal of Anesthesiology Clinical Pharmacology. October-December 2013; 29(4).

8. Athar M, Ahmed SM, Ali S, Siddiqi OA. Levobupivacaine: a safer alternative. J Curr Res Sci Med 2016;2:3-9.

9. Wahab EHA, Soliman SM, Amen SM, ElShehdwy SR. Comparitive study between levobupivacaine versus bupivacaine in spinal anesthesia for cesarean sections. Tanta Med J 46:232-38.

10. Naithani U, Malleshappa K, Madhanmohan, Meena P. Comparison of intrathecal isobaric levobupivacaine with hyperbaric bupivacaine in spinal anesthesia for lower limb orthopedic surgeries. International Journal of Health Sciences \& Research. 2015;5(10)

11. Metta R, Chakravarthy PK, Babu HK, Rani JP, Arun P. Comparison of isobaric levobupivacaine with hyperbaric bupivacaine inspinal anesthesia in patients undergoing Lower Abdominal Surgeries. JMSCR December 2019;07(12).

12. Babu R, Harshavardhan. Intrathecal isobaric levobupivacaine $0.5 \%$ as an alternative for hyperbaric bupivacaine $0.5 \%$ for spinal anesthesia in elective lower segment caesarian section - a randomised double blind study. International Journal of Health Sciences \& Research September 2016;6(9).

13. Deori AK, Das A, Borgohain D, Bora D, Saikia A, Tiwari PK. A comparative study of spinal anaesthesia with levobupivacaine and hyperbaric bupivacaine for cesarean sections. International Journal of Contemporary Medical Research 2016;3(7):1902-05.

14. Sundarathiti $\mathrm{P}$ et al. Comparison of intrathecal bupivacaine, levobupivacaine for cesarean section. J Med Assoc Thai 2014; 97 (7): 710 6. 